\title{
Processo de obtenção de álcool de segunda geração a partir de material lignocelulósico
}

\author{
Gomes F. D. ${ }^{1^{*}}$; Pinheiro I. R. ${ }^{2}$; Radael L. C. R. ${ }^{1}$; Campos P. R. ${ }^{1}$, Souza R. F. ${ }^{1}$ \\ 1 Discente Graduando em Engenharia Química, Universidade Federal do Espírito Santo, Alegre, ES, Brasil. \\ 2 Docente no Centro de Ciências Agrárias e Engenharias, Universidade Federal do Espírito Santo, Alegre, ES, Brasil. \\ *e-mail: felix.gomes@outlook.com
}

\begin{abstract}
Resumo
Visando a obtenção de uma alternativa viável para substituição do petróleo como fonte primária de energia, os processos de produção de biocombustíveis mostram-se promissores. Esses são convencionalmente feitos a partir de açúcares e óleos extraídos das plantas, em sua maioria as grandes culturas como o milho e a cana de açúcar. A fim de ter competitividade com os combustíveis fósseis, é necessário ampliar a atual escala de produção, levando em conta fatores como as áreas de cultivo e limitação da produção. Por outro lado, a produção convencional gera um grande volume de materiais não reaproveitados, como o bagaço da cana de açúcar e a palhagem do milho. Esses materiais são classificados como biomassa e, no caso das plantas, há uma constituição de frações variadas de celulose, hemicelulose e lignina, podendo estes serem convertidos em variadas fontes de energia. Com os avanços nas pesquisas, comprovou-se a possibilidade de produzir biocombustíveis a partir destes materiais, sendo o principal, o bioetanol de segunda geração. O processo de produção do bioetanol se baseia nas etapas iniciais de pré-tratamento da biomassa e hidrólise para então seguir a rota convencional de fermentação alcoólica e destilação.
\end{abstract}

Palavras-chave: bioetanol, biomassa, celulose.

\begin{abstract}
In order to obtain a viable alternative to replace petroleum as a primary energy source, biofuel production processes are promising. These are conventionally made from sugars and oils extracted from plants, mostly large crops like corn and sugar cane. In order to be competitive with fossil fuels it is necessary to expand the current scale of production, taking into account factors such as areas of cultivation and production limitation. On the other hand, conventional production generates a large volume of nonrecycled materials, such as sugar cane bagasse and corn straw. These materials are classified as biomass and in the case of plants, these are constituted by various fractions of cellulose, hemicellulose and lignin, and these can be converted into various energy sources. With the advances in the researches, the possibility of producing biofuels from these materials was proved, being the main one, the secondgeneration bioethanol. The bioethanol production process is based on the initial stages of biomass pretreatment and hydrolysis to then follow the conventional path of alcoholic fermentation and distillation.
\end{abstract}




\section{Introdução}

Com o processo de desenvolvimento e busca por uma melhor qualidade de vida, exige-se uma quantidade maior de recursos para a produção de energia, alimentos e insumos. A principal fonte energética mundial é o petróleo, porém este recurso é limitado e não renovável, diante disso torna-se necessário procurar por fontes de energia renovável. Os biocombustíveis passaram a ser uma possível alternativa para substituir o petróleo, esses estão limitados a produção agrícola, que apesar de serem renováveis não suprem toda a demanda energética oriunda do petróleo. A principal fonte de biocombustíveis são as grandes culturas, como os cereais e a cana de açúcar, que exigem grandes extensões de terras para serem cultivadas. (ROSA e GARCIA, 2009).

Segundo o relatório de 2011 da IEA - International Energy Agency -, o consumo de biocombustíveis pode aumentar de forma sustentável, estimando um aumento de 55 milhões de toneladas equivalentes de petróleo (MTEP) em 2011 para 750 MTEP em 2050, isto significa que a adição de biocombustível nos combustíveis fósseis deve passar de $2 \%$ para $27 \%$ em 2050. Além disso, tecnologias de biocombustíveis, produzidos principalmente a partir de biomassa lignocelulósica, precisam ser implantadas comercialmente nos próximos dez anos, devendo fornecer a maior parte dos biocombustíveis até 2050 .

Os materiais lignocelulósicos como, por exemplo, o bagaço de cana-de-açúcar, a palha de arroz, a palha de trigo, o sabugo de milho, a casca de aveia e as aparas de eucalipto, são oriundos de resíduos da agroindústria e de atividades da exploração florestal, e são também os recursos orgânicos renováveis mais abundantes da terra, representando a maior porção do carbono total fixado por fotossíntese (ARISTIDOU e PENTTILÄ, 2000).

O potencial de aproveitamento da biomassa lignocelulósica baseia-se em sua composição química; pois, independente de sua origem, os materiais lignocelulósicos contêm celulose, hemicelulose e lignina como principais componentes, em proporções que variam de 40 a $50 \%, 25$ a $35 \%$ e 15 a $25 \%$, respectivamente (FENGEL e WOOD, 1984).

Diversos processos têm sido explorados nos últimos anos, com o objetivo de hidrolisar os polissacarídeos celulose e hemicelulose em glicose e xilose, respectivamente. A maioria dos métodos utilizados tende ao uso de enzimas microbianas ou ácido minerais em concentrações variadas (BALAT et al., 2008). Contudo, antes do material ser hidrolisado, o mesmo deve ser submetido a uma etapa de prétratamento.
O alvo da tecnologia de pré-tratamento é remover barreiras estruturais e composicionais dos materiais lignocelulósicos (lignina), promovendo uma melhora na percentagem de hidrólise e aumento dos rendimentos de açúcares fermentescíveis a partir da celulose e hemicelulose (MOSIER et al., 2005).

\section{A Produção de Bioetanol}

A grande vocação do Brasil para a produção de álcool faz dele o maior produtor de cana-de-açúcar do mundo. Embora transpareça progresso e divisas para o país, tais cifras trazem como consequência um grande problema, que é a geração de 128 milhões de toneladas de bagaço ao ano. (UNICA, 2013). Com isso, aumentou-se o investimento em tecnologias para 0 aproveitamento do bagaço da cana, assim usando-o como nova matéria prima na produção do combustível. Segundo a empresa GranBio, basicamente a perca da sacarose ainda constituída no bagaço após a moagem é um gargalo significativo em quantidade no custo final da produção. Com a adição do processo de obtenção do etanol de segunda geração, a indústria reduzirá esse gargalo, otimizando seu processo de produção.

\subsection{Matéria Prima}

O bagaço é de natureza lignocelulósica e composto por um arranjo em porções variadas de celulose, lignina e hemicelulose (SILVA, 2010). Sua estrutura está representada na figura 2.1 .0 .

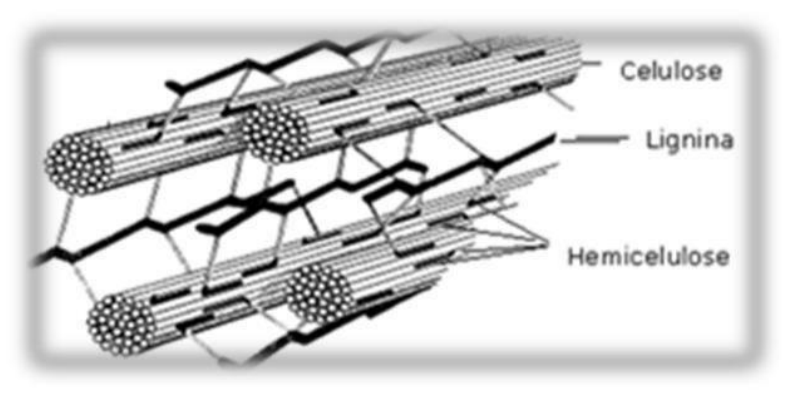

Figura 2.1.0: Esquema estrutural simplificado das fibras do material lignocelulósico.

Fonte: (LEE, 1997 apud SILVA, 2010).

\subsubsection{Celulose}

A celulose é um polissacarídeo linear de cadeia homogênea, constituído por unidades de celobiose unidas por ligações glicosídicas. As cadeias de celulose formam fibrilas elementares que se caracterizam por uma região cristalina de configuração ordenada e pela região amorfa menos ordenadas e sujeita a sofrer o processo de hidrolise (GOMEZ, 1985 apud DRABER, 2013). 
A estrutura da celulose esta ilustrada na figura 2.1.1:

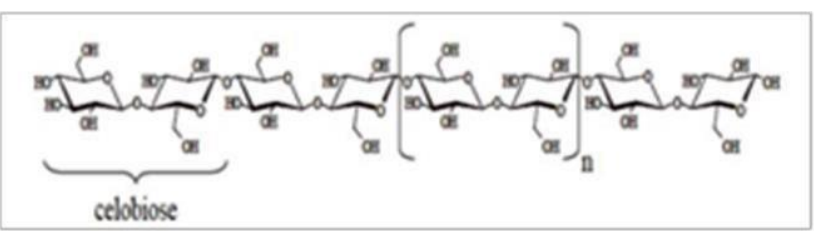

Figura 2.1.1: Representação da cadeia linear da celulose, formada de várias unidades consecutivas de celobiose.

Fonte: (TIMAR-BALÁZSY, 1998 apud DRABER, 2013).

\subsubsection{Hemicelulose}

A hemicelulose é um polissacarídeo heterogêneo composto por pentoses (xilose, ramnose e pentose), hexoses (glicose, manose e galactose) e ácidos urônicos (cidos-4-O-metil-glucurônico e galacturônico). A xilose corresponde a maior parte de sua composição. (BALAT et al., 2008 apud DRABER, 2013).

A figura 2.1.2 ilustra a estrutura dos componentes da hemicelulose.

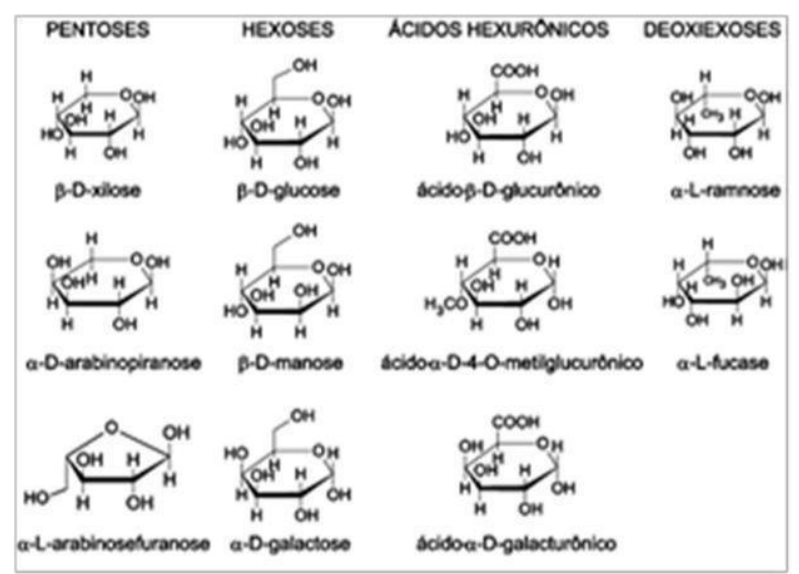

Figura 2.1.2. Componentes da fração hemicelulose.

Fonte:(MORAIS, 2005 apud SILVA, 2010).

\subsubsection{Lignina}

Diferente dos compostos hemicelulose e celulose a lignina não é classificada como um polissacarídeo, isso implica características peculiares como resistência a processos fermentativos e degradação. Tendo origem na polimerização desidrogenada do álcool coniferílico, ela é constituída por polímeros fenilpropanóides que estão dispostos em sua cadeia de forma irregular (HENDRIKS e ZEEMAN, 2009 apud DRABER, 2013).

A figura 2.1.3 representa a estrutura da lignina.

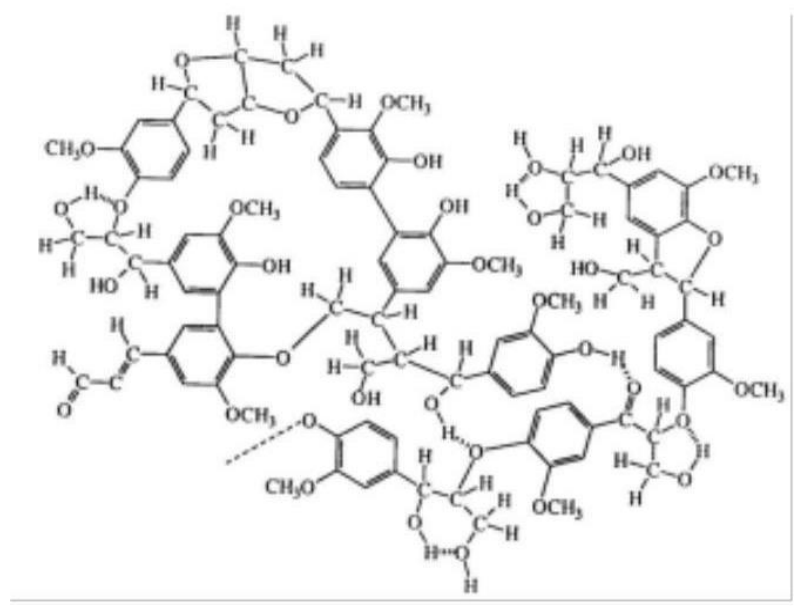

Figura 2.1.3. Representação estrutural da lignina. Fonte: (ROSA e GARCIA, 2009).

\subsection{Processo de Produção}

Segundo Rosa e Garcia (2009), o processo de obtenção de álcool a partir de materiais lignocelulósicos seguem em linhas gerais como exemplificado na figura 2.2.0:

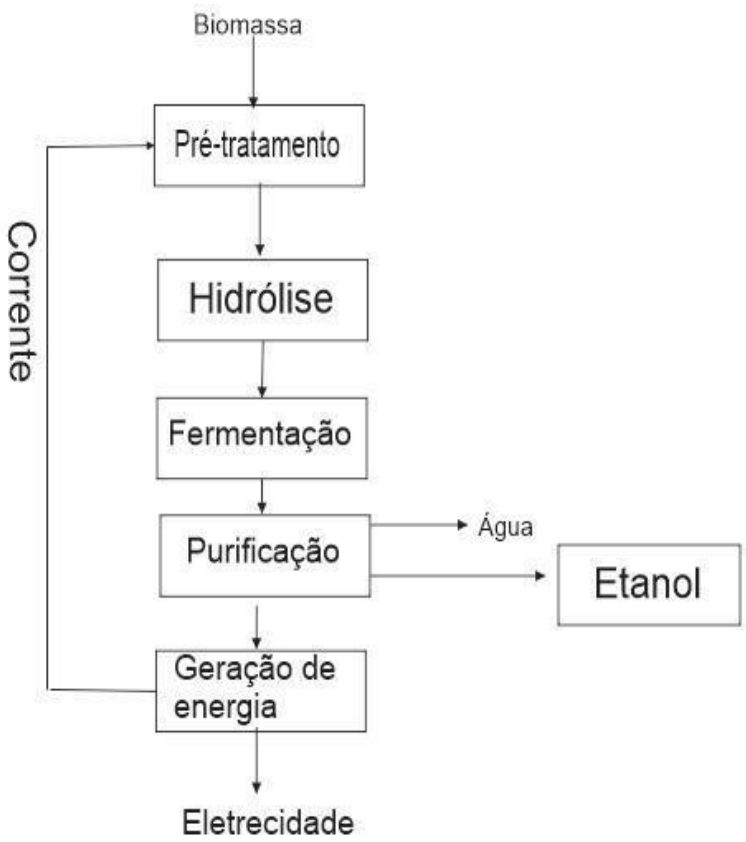

Figura 2.2.0. Fluxograma do processo de obtenção de álcool a partir de biomassa

Fonte: modificado: (Hamelinck et al. 2005 apud ROSA e GARCIA, 2009). 


\subsubsection{Pré-tratamento}

O objetivo central da etapa de pré-tratamento será destruir a estrutura celular das plantas promovendo a separação das frações de hemicelulose, lignina e celulose de modo a permitir as operações posteriores (ROSA e GARCIA, 2009).

[...] Existem diversos tipos de pré-tratamentos, com diferentes rendimentos e efeitos distintos sobre a biomassa e consequente impacto nas etapas subsequentes. Dentre os vários métodos de pré-tratamento, os mais comumente utilizados são pirólise, Steam explosion, Amomnia fiber explosion, CO explosion, ozonólise, hidrólise ácida, hidrólise alcalina, hidrólise enzimática, deslignificação oxidativa e processo Organosolv (SUN \& CHENG, 2005, apud SILVA, 2010 p. 12).

\subsubsection{Hidrólise Enzimática}

A conversão da celulose à glicose enzimaticamente é catalisada por um grupo de enzimas denominadas celulases, as quais rompem as ligações glicosídicas das microfibrilas de celulose, resultando na liberação de oligossacarídeos, celobiose e glicose. Este processo é de crucial importância na ciclagem de nutrientes, uma vez que tal polímero representa cerca de $40 \%$ do material de origem vegetal (DILLON, 2004 apud SANTOS, 2012).

No processo enzimático, por sua vez, a biomassa lignocelulósica é primeiramente pré-tratada para aumentar a acessibilidade ao ataque enzimático, pois a celulose é protegida por outros materiais resistentes ao ataque químico como a lignina e a hemicelulose. A quebra desses polímeros são as dificuldades maiores no processo da hidrólise (ROSA e GARCIA, 2009).

\subsubsection{Fermentação e Destilação}

É no processo de fermentação que é realizado a conversão dos açúcares presentes na solução resultante da hidrólise, utilizando a levedura Saccharomyces cerevisiae. Antes de ser submetido a etapa de fermentação o material deve passar por análises químicas e físicas para ser determinados parâmetros tais como: peso específico, sacarose real e aparente, açúcares redutores, açúcares totais, pureza, coeficiente glucósico e salino, acidez, entre outros. (SILVA 2012).

$\mathrm{Na}$ maioria das usinas a etapa de fermentação é realizada através do processo de Malle-Boinot, cuja característica principal é a recuperação de leveduras através da centrifugação do vinho.
O tempo de fermentação varia entre 4 e 12 horas com o objetivo de as leveduras consumirem todo o açúcar, transformando-o assim em um vinho fermentado com 7 a $10 \%$ de álcool nas dornas.

Em sequência o vinho é levado a torre de destilação onde o etanol é separado da vinhaça através dos seus pontos de volatilidade. Na destilação uma fase vapor entra em contato com a fase líquida, e há transferência de massa do líquido para o vapor e deste para aquele.

O líquido e o vapor contêm, em geral, os mesmos componentes, mas em quantidades relativas diferentes. Ocorre transferência simultânea de massa do líquido pela vaporização, e o vapor pela condensação. $O$ efeito é o aumento da concentração do componente mais volátil no vapor e o do componente menos volátil do líquido.

A figura 2.2.3 ilustra o processo de fermentação onde ocorre também o reciclo, destilação e controle de inibidores.

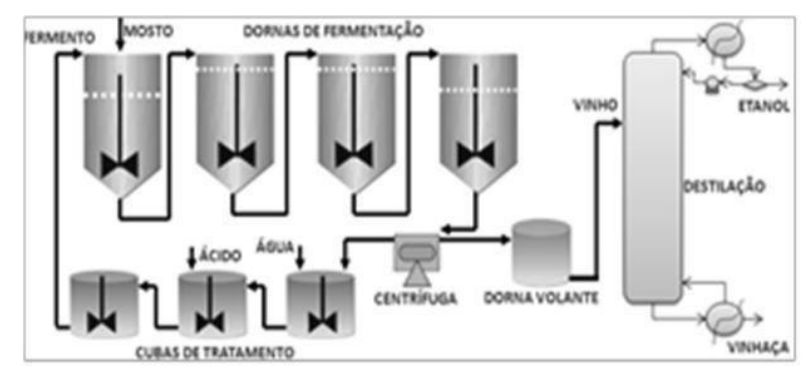

Figura 2. 2.3: Processo de fermentação do tipo Malle-Boinot

Fonte: Adaptado de (FRITZEN et al., 2012 apud SILVA 2012).

\section{Conclusões}

O uso do bioetanol tem suscitado grande interesse devido à alta dos preços, e problemas ambientais. Por ser um produto renovável, este contribui para a redução do efeito estufa e diminui substancialmente a poluição do ar. Atualmente, este é o principal biocombustível empregado mundialmente, correspondendo por $10 \%$ da energia mundial. (IEA, 2010).

De fato, o Brasil apresenta vantagens competitivas em relação aos outros países, como, o menor custo, e a fácil disponibilidade de grandes quantidades de matéria-prima. Com essa inovação gera-se maior potencial energético, tornando bem mais eficiente $o$ processo, e expandindo a indústria sucroalcoleira no país.

\section{Referências}

[1] ROSA, S. E. S.; GARCIA, J. L. F. O etanol de segunda geração: limites e oportunidades. Revista do BNDS 32, p 117-156, dezembro 2009. 
[2] ARISTIDOU, A.; PENTTILÄ, M., 2000. Metabolic engineering applications to renewable resource utilization. Current Opinion in Biotechnology, v. 11, p. 187-98.

[3] FENGEL, D.; WEGENER G. WOOD: Chemistry, ultrastruture, reactions. Berlim, 1984. 613 p. Disponível em: <http:// catalogur. Nla. Gov.au/ Record / 876242 >. Acessoem 16 jul. 2013.

[4] BALAT, M.; BALAT, H.; ÖZ, C. Progress in bioethanol processing. Progress in Energy and Combustion Science, v. 34, n. 25, p. 551-553, 2008.

[5] MOSIER, N. et al. Features of promising technologies for pretreatment of lignicellulosic biomass. Bioresourse Technol, v. 96, p. 673-686, 2005.

[6] SILVA,N. L. C.Produção de bioetanol de segunda geração a partir de biomassa residual da indústria de celulose. 2010. Dissertação (Mestrado em Tecnologia de Porcessos Químicos e Bioquímicos) - Universidade Federal do Rio de Janeiro, Escola de Química, Rio de Janeiro, 2010.

[7] DRABER, K. M. M. Etanol de segunda geração já é realidade. Monografia da Graduação do Curso de Engenharia Bioquímica, Universidade de São Paulo Escola de Engenharia de Lorena, Novembro 2013.

[8] IEA-InternationalEnergy Agency. Renewables bioenergy, 20 April 2011, Wasington D.C. Disponível em: <http://www.iea.org/newsroomandevents/pressreleases /2011/april/biofuels-can-provide-up-to-27-of-worldtransportation-fuel-by-2050-iea-report-.html>.

Acesso: Junho, 2016.

[10] SILVA, J. I. S. da. Simulação dinâmica do processo de destilação de bioetanol em simulador baseado em equações (emso). Dissertação (Mestrado em Engenharia Química) - Universidade Federal de São Carlos, São Carlos-SP, 2012.

[11] JANK, M. S. O etanol na conferência de biocombustíveis. 2008. Disponível em:

$<$ http://www.unica.com.br/opiniao>.

Acesso: Junho, 2016.

[12] TSIGIE, Y. A.; WU, C.; HUYNH, L. H.; ISMADJI, S.; JU, Y. Bioethanol production from Yarrowia lipolytica Po1g biomass. Bioresource Technology, v.145, p.210 216, 2013.

[13] ALVIRA, P.; TOMÁS-PEJÓ, E.; BALLESTEROS, M.; NEGRO, M. J. Pretreatment technologies for an efficient bioethanol production process based on enzymatic hydrolysis: A review. Bioresource Technology, v.101, p.4851-4861, 2010.

[14] MAEDA, R. N. PRODUÇÃO DE CELULASES POR Penicillium funiculosum EM FERMENTAÇÃO SUBMERSA DE BAGAÇO DE CANA PRÉ-TRATADO E SUA APLICAÇÃO NA PRODUÇÃO DE ETANOL DE SEGUNDA GERAÇÃO. Tese (Doutorado) - Curso de Tecnologia de Processos Químicos e Bioquímicos, Escola de Química, Universidade Federal do Rio de Janeiro, Rio de Janeiro, 2010. 